\title{
Medellín e o imperativo da Nova Evangelização
}

\section{Medellin and the Imperative of the New Evangelization}

\section{Cleusa Caldeira*}

\section{RESUMO}

Com este artigo, desejamos recuperar a origem e o sentido originário da expressão "nova evangelização", gestada no contexto da Igreja Católica na América Latina, sob o espírito de renovação do Concílio Ecumênico Vaticano II, na Conferência de Medellín em 1968. Não é raro atribuir a João Paulo II a sua paternidade, visto que inúmeras vezes o pontífice fez uso da expressão. Mas, não significa que ele tenha captado e reconhecido sua verdadeira face. Seu projeto, em grande medida, parece que esteve distante do espírito do Vaticano II e da tradição libertadora latino-americana. Evidente que o conceito "nova evangelização", plasmado em Medellín, tem conotação específica. Entretanto, parece que determinados processos de evangelização levados a cabo pela própria Igreja Católica, sobretudo a partir dos anos 1990, esteve distante do seu sentido originário. Nem toda denominada "nova evangelização" é realmente nova, tanto fora como aqui em nosso Continente. Entretanto, ainda que "brasa sob cinzas", a nova evangelização, preconizada por Medellín, existe e resiste contra toda esperança. Por isso, o imperativo por uma "conversão pastoral", da Conferência de Aparecida, parece ser o melhor caminho para se pensar na vigência da "nova evangelização" em tempos pós-modernos. Palavras-chave: Nova Evangelização. Vaticano II. Medellín. América Latina. Pós-modernidade.

\section{ABSTRACT}

With this article, we wish to recover the origin and the original meaning of the expression "new evangelization", born in the context of the Catholic Church in Latin America, under the spirit of renewal of the Second Vatican Ecumenical Council at the Medellin Conference in 1968. It is not uncommon to attribute to John Paul II his paternity, since innumerable times the pontiff made use of the expression. But, it does not mean that he has captured and recognized his true face. His project, to a large extent, seems to have been distant from the spirit of Vatican II and the Latin American liberating tradition. It is evident that the concept "new evangelization", shaped in Medellín, has specific connotation. However, it seems that certain processes of evangelization carried out by the Catholic Church itself, especially since the 1990s, were far from their original meaning. Not every so-called "new evangelization" is really new, both outside and here on our Continent. However, even though "ember under ashes", the new evangelization, praised by Medellín, exists and resists against all hope. For this reason, the imperative for a "pastoral conversion" of the Aparecida Conference seems to be the best way to think about the validity of the "new evangelization" in postmodern times. Keywords: New Evangelization. Vatican II. Medellín. Latin America. Postmodernity.

\footnotetext{
* Doutorado em teologia pela Faculdade Jesuíta de Filosofia e Teologia (FAJE), 2017. Pós-doutorado em Teologia pela Pontifícia Universidade Católica do Paraná, 2018. Bolsista CAPES. ORCID: https://orcid.org/0000-0001-7202-0682.<cleucaldeira@gmail.com>
} 


\section{INTRODUÇÃO}

A primeira evangelização na América Latina se fez sob o signo da sujeição, visto que se processou no bojo do projeto de invasão e colonização: prevaleceu a "lógica da violência". Porém, como todo acontecimento histórico, ela é ambígua: permeada de luzes e sombras. As sombras, com efeito, dizem respeito ao genocídio cultural e religioso que sofreram os povos originários e também os africanos sequestrados e escravizados $^{1}$. Ambos tiveram seus costumes culturais e religiosos demonizados. Os povos originários foram obrigados a cortarem suas raízes culturais, suas tradições religiosas e foram lançados à margem social. Até hoje permanece grande desprezo pela cultura e religião dos povos originários. Em relação ao povo negro escravizado, a violência foi ainda maior. Não bastasse a violência de sua deportação e escravidão, foi-se forjando um sistema cultural e religioso para legitimar sua escravidão ${ }^{2}$. De modo que o negro se tornou a moeda de troca por excelência sob a racionalidade moderna eurocêntrica.

Diversa da escravidão antiga, uma instituição ao lado de muitas outras na sociedade e no Estado, a escravidão americana que, em determinados países, alcançou $90 \%$ da população (em ilhas como Barbados, Martinica, Guadalupe ou Haiti), foi a instituição-chave e estruturante dessas sociedades, modelando sua economia, suas relações sociais e jurídicas, o caráter do Estado e da Igreja. Tudo estava em função da legitimação, consolidação e manutenção do regime escravista ${ }^{3}$.

Leonardo Boff questiona se uma evangelização pode conservar seu estatuto teológico de evangelização quando faz uso da coerção, da violência e da negação da alteridade 4 . Diante disso, se pergunta se a primeira evangelização na América Latina já não foi de partida uma "velha" evangelização.

Apesar de toda violência da primeira evangelização no Continente, houve luzes. Isso por que, em última instância, "o sujeito último da evangelização, aquele que toca o coração e, por seu espírito, implanta as sementes do Verbo, inclusive onde não foi 'pregado' o Evangelho: é sempre Deus mesmo"s. Também, houve cristãos que evangelizaram no cotidiano da vida. Com efeito, esta foi uma interlocução totalmente espontânea e livre, na qual se transmitiu o Deus que realmente agia em suas vidas, não o Deus da proclamação oficial autoritária. Como resultado desse contato entre cristãos sinceros - cristãos pobres - e a população autóctone, brotou e floresceu a religião popular em solo latino-americano, que hoje se constitui no "substrato religioso" de nossa cultura. Pois, por meio dela os pobres, os colonizados, os negros escravizados,

\footnotetext{
${ }^{1}$ Usamos o termo "africanos escravizados" para enfatizar que se trata de pessoas livres que foram escravizadas e não de pessoas que já eram escravas, como foi - posteriormente- desenvolvido todo um sistema teológico para legitimar a escravidão dos africanos e africanas transportados à força ao Continente Americano. Entre o século XVI e metade do século XIX, cerca de 11 milhões de africanos escravizados entraram na América, metade para as plantações milionárias do Caribe espanhol, inglês, francês, holandês, uns $40 \%$ para o Brasil e o restante distribuídos entre os demais países (BEOZZO, J. O. 500 Anos de Evangelização da América Latina: o que podemos aprender de suas luzes e sombras, p. 305).

2 Beozzo cita o caso do batismo cristão que "converteu-se" de sacramento de libertação em sacramento de escravidão. Era preciso conjugar batismo e escravidão. Para isso foram feitas três manobras essenciais: a) acertar o pressuposto - falso- de que as pessoas já eram escravas na África e ao transportá-las para a América não lhes cometia nenhuma injúria; b) aceitar a pressuposição de uma radical mudança, na África estas pessoas eram escravas e pagãs e, ao passarem à América, continuavam sim escravas, mas convertiam-se em cristãs; c) implantar e sacralizar o dualismo, separando o corpo e alma, entre vida presente e vida futura, para legitimar o batismo que libertaria a alma do negro escravizado, mas o mantinha seu corpo escravizado; lançando a promessa de uma vida melhor para além corpo (BEOZZO, J.O. 500 Anos de Evangelização da América Latina, p. 309).

${ }^{3}$ BEOZZO, J.O. 500 Anos de Evangelização da América Latina, p. 305.

${ }^{4}$ Cf. BOFF, L. O Conflito dos Modelos de Evangelização para a América Latina: Reflexões a propósito dos 500 anos, p. 349.

${ }_{5}^{5}$ TABORDA, F.S. J. Evangelización, p. 62.
} 
os indígenas e os mestiços encontraram alento para suportar a miséria e ressignificar a própria existência dentro do sistema opressor que vigorava e ainda vigora no Continente; agora, porém, com outra aparência, sob a máscara do capitalismo mundial.

Não se pode esquecer que, sempre houve espíritos proféticos que protestaram e resistiram ao caráter perverso da colonização. E, por isso, foram perseguidos, exilados e, muitos, mortos. Tais como Bartolomeu de Las Casas, o bispo Antonio Valdivieso na Nicarágua, o Mons. Oscar Arnulfo Romero em El Salvador e, tantos outros mártires da história da evangelização na América Latina. Enfim, a "nova evangelização" lança raízes nesta tradição profético-pastoral; sua forma se faz sob o signo da libertação.

\section{FILHA LEGÍTIMA DA IGREJA NA AMÉRICA LATINA É A "NOVA EVANGELIZAÇÃO"}

A Conferência Episcopal latino-americana de Medellín foi convocada por Paulo VI que fez questão de inaugurá-la, em Bogotá (1968). O objetivo central dessa Conferência era colocar a Igreja na América Latina no eixo dessa nova ordem renovadora do Concílio Ecumênico Vaticano II. O temor era que o Concílio, plasmado à luz da teologia moderna europeia, passasse à margem no Continente latino-americano.

Os bispos latino-americanos, contudo, foram muito mais longes. Eles fizeram uma verdadeira inculturação do Vaticano II. "A importância de Medellín se deve ao fato dos bispos da América Latina terem acolhido as propostas do Vaticano II, encarnando-as no contexto do subcontinente, marcado pela injustiça e a pobreza"'. Isso se tornou possível, por que os bispos - seguindo as orientações de Paulo VI - assumiram o Vaticano II não apenas como um "ponto de chegada", e sim como "ponto de partida".

Como resultado da "recepção criativa" do Vaticano II, a Conferencia em Medellín usa pela primeira vez a expressão "nova evangelização". No início do Documento, na Mensagem aos Povos da América Latina, os bispos afirmam a necessidade de "alentar uma nova evangelização [...] para obter uma fé mais lúcida e comprometida"7. Mais adiante, os bispos vão dizer que para isso será preciso superar o modelo pastoral pré-conciliar e de cristandade, a "pastoral de conservação", "baseada numa sacramentalização com pouca ênfase na prévia evangelização"; a pastoral de "uma época em que as estruturas sociais coincidiam com as estruturas religiosas [...]"

Essa "nova evangelização", plasmada pela Igreja Católica na América Latina, tem conotação específica. Medellín gera a evangélica opção pelos pobres, como um novo modelo de Igreja - pobre e em pequenas comunidades- as CEBs, a Teologia da Libertação, a Vida Religiosa inserida, a ruptura com o esquema desenvolvimentista e a leitura crítica da realidade: violência institucionalizada e pecado social; etc.

Em Medellín "nova evangelização" é uma categoria que expressa a exigência de levar adiante a renovação do Vaticano II, por meio de um novo modelo de pastoral, isto é, passar de uma "pastoral de conservação" à uma pastoral transformadora.

Em 1974, reuniu-se o Sínodo dos Bispos sobre "A evangelização no mundo contemporâneo". Seus resultados foram publicados na Encíclica "Exortação Evangelii Nuntiandi" por Paulo VI, em 1975. Esta encíclica é considerada a "Carta Magna” da evangelização". Será, pois, sob o impacto do protagonismo dos bispos da América Latina

\footnotetext{
${ }^{6}$ BRIGHENTI, A. A Igreja na América Latina e a "recepção criativa" do Concílio Vaticano II, p. 229-255.

${ }^{7}$ II CONFERÊNCIA GERAL DO EPISCOPADO LATINOAMERICANO. Medellín. Conclusões, p. 39.

${ }^{8}$ II CONFERÊNCIA GERAL DO EPISCOPADO LATINOAMERICANO. Medellín. Conclusões, $6,1$.

${ }^{9}$ MELGUIZO YEPES, G. La nueva evangelización. A Igreja na América Latina e a "recepção criativa" do Concílio Vaticano II, p. 10.
} 
que recriaram a Igreja no Continente, que Paulo VI fala da necessidade de suscitar "tempos novos de evangelização"10. Este importante documento respaldará os bispos em Puebla, em meio a tensões, na continuação da "recepção criativa" do Vaticano II. Puebla afirma, então, “... situações novas $(A G 6)$, que nascem de mudanças socioculturais, requerem uma nova evangelização"

\section{CRITÉRIOS DE AUTENTICIDADE DE UMA "NOVA EVANGELIZAÇÃO"}

A partir das considerações acima, pode-se explicitar dois grandes critérios de autenticidade de uma "nova evangelização", em estreita comunhão com a tradição libertadora. O primeiro é sintonia com o espírito de renovação do Vaticano II, isto é, uma "nova evangelização" autêntica assume o Concílio como "ponto de partida" e não "ponto de chegada". O segundo é harmonia com a tradição latino-americana, em especial Medellín e Puebla, na perspectiva do arggionamento como processos de encarnação em meio a história fraturada da humanidade.

\section{PROCESSOS DE INVOLUÇÃO ECLESIAL (?)}

João Paulo II, não raro, é considerado "pai" da "nova evangelização". Contudo, o que ele fez foi relançar como slogan, "ordem do dia", "ideal e programa" o termo cunhado pelos bispos na América Latina. O pontífice em seu discurso ao CELAM no Haiti, em 1983, fala pela primeira vez em solo latino-americano de "nova evangelização". Na ocasião, consciente da difícil tarefa diante dos bispos que recriaram a Igreja na América Latina, retoma a Evangelii Nuntiandi ao falar de "novo ardor", "novo método" e "novo conteúdo/expressão". Entretanto, ele não explicita essas três características, parece mais "um simples recurso retórico" 12 . João Paulo II, com efeito, foi o pontífice que mais fez uso da expressão "nova evangelização". No entanto, parece que seu pontificado marca o início de um longo processo de involução eclesial na Igreja católica.

Em 2012, o Sínodo dos Bispos sobre "a nova evangelização para a transmissão da fé cristã", sob o pontificado de Bento XVI, parece ratificar esse processo de involução eclesial. No discurso de abertura o pontífice explicita três sentidos de evangelização. A primeira é a evangelização ordinária. A segunda, a missão ad gentes, isto é, a proclamação do Evangelho para aquelas pessoas que ainda não conhecem a Jesus Cristo e a Sua mensagem de salvação. E a terceira, a "nova evangelização", destinada às pessoas que, embora batizadas, se distanciaram da Igreja e vivem sem levar em conta prática cristã.

Ratificando os processos de involução eclesial, no documento base para os estudos, podem ser percebidos resquícios de neocristandade no Instrumentum laboris. Nele a meta da evangelização é chegar aos cristãos descristianizados, sobretudo europeus. As expressões estão ligadas a reconstrução do esfarrapado tecido cristão da sociedade. $\mathrm{O}$ "método" é ênfase no primeiro anúncio, apologética. E, por fim, o "novo ardor" tem a ver com o entusiasmo, ou seja, a "alegria de ser católico"13.

\footnotetext{
${ }^{10}$ PAULO VI, Exortação Apostólica Pós-Sinodal Evangelii nuntiandi (8.12.1975), n. 2.

${ }^{11}$ III CONFERENCIA GENERAL DEL EPISCOPADO LATINO-AMERICANO, Puebla. Conclusões, n. 366.

${ }^{12}$ TABORDA, F.S. J. Evangelización, p. 60.

${ }^{13}$ BRIGHENTI, A. Nueva y antiga evangelización. El imperativo de una conversión pastoral, p. 67-101.
} 


\section{NEM TODA DITA “NOVA EVANGELIZAÇÃO” É REALMENTE NOVA}

Como fruto desse longo período de involução eclesial, proliferam modelos de pastoral que, embora façam uso do termo "nova evangelização", de antemão já se encontram ultrapassados. De um lado, "porque pode estar repetindo modelos esclerosados do passado", por outro lado, "porque o modelo apresentado não expressa a novidade perene da mensagem evangélica, na contingência de um novo tempo e de um novo contexto" 14 . Projetos chamados de "nova evangelização" podem inclusive mascarar, conscientes ou não, formas antigas de evangelização, neocolonialistas, com a única diferença de que o centro colonizador agora já não se situa em Roma ou Portugal, mas sim no Texas e Holanda ${ }^{15}$.

Assim, são os projetos Lumen 2000 e Evangelização 2000, tais projetos remontam antigos modelos de evangelização ligados a projetos de colonização. Nesses projetos, a novidade vem dos meios usados, porém, o conteúdo é tradicional. Neles repetem o modelo tridentino, porém, com a plástica moderna.

\section{QUANDO FALAR DE “NOVA EVANGELIZAÇÃO”}

Evidente que "nova evangelização" não se refere ao conteúdo da verdade cristã - o Evangelho- como se este tivesse perdido a sua relevância, a sua capacidade de transformar as vidas, as estruturas, as culturas e as religiões. A novidade da evangelização é contínua ou do contrário não se produz evangelização. Mas, a exigência de "nova" está relacionada "à transmissão da fé às novas gerações" ${ }^{16}$. Isto é, "nova evangelização se impõe diante do desafio de manter sempre viva e atual a novidade do Evangelho" 17 . Evidente que, o "tesouro da mensagem não envelhece, mas de barro é a roupagem ou o invólucro que o torna presente na precariedade da história"18.

Em outras palavras, a evangelização ocorre sempre num processo de encontro entre a sempre ambígua realidade histórico-social e a mensagem cristã. E, por isso, diante da mudança de época emerge a exigência de uma "nova evangelização", que consiga manter a novidade do Evangelho em todos os tempos e lugares. Com a mudança de época emerge, também, um novo sujeito e este, com efeito, produz alterações significativas no contexto sociocultural. Por isso a "nova evangelização" necessita converte-se em um tema teológico-pastoral.

\section{REAFIRMAR A TRADIÇÃO LIBERTADORA LATINO-AMERICANA}

Em meio aos processos de involução eclesial, iniciados a partir da década de 90, a Igreja na América Latina retoma o processo de "recepção criativa" do Vaticano II com a Conferência de Aparecida, em 2007. Seguindo o método ver-julgar-agir, a modo do Vaticano II, o ponto de partida é os "sinais dos tempos", presentes em uma realidade ambígua e contraditória ${ }^{19}$.

\footnotetext{
${ }^{14}$ BRIGHENTI, A. Por uma evangelização realmente nova, p. 85.

${ }^{15}$ TABORDA, F.S. J. Evangelización, p. 38).

${ }^{16}$ MIRANDA, M. F. Em vista da nova evangelização, p. 14.

${ }^{17}$ BRIGHENTI, A. Por uma evangelização realmente nova, p. 84.

${ }^{18}$ DUQUOC, C. Je crois em l'Église, 1999.

${ }^{19}$ Cf. BRIGHENTI, A. A desafiante proposta, p. 7
} 
O objetivo mais genuíno da Conferência de Aparecida é o de conseguir que a Igreja, peregrina na América Latina e no Caribe, chegue a ser verdadeiramente uma Igreja em estado permanente de missão. Para Aparecida, "a firme decisão missionária de promoção da cultura de vida deve impregnar todas as estruturas eclesiais e todos os planos de pastoral, em todos os níveis eclesiais, bem como toda a instituição, abandonando as estruturas ultrapassadas" "20. Por isso, Aparecida, em sintonia com Medellín, entende a conversão pastoral como a passagem de uma pastoral de cristandade, de sacramentalização, de conservação, a uma pastoral de pós-cristandade, evangelizadora, "decididamente missionária" 21 . Daí a exigência de Aparecida de uma "conversão pastoral" e "renovação eclesial".

Afirma Aparecida que todos, na Igreja, estão chamados a assumir uma atitude de permanente conversão pastoral (365), pois a ação eclesial não pode prescindir do contexto histórico onde vivem seus membros (367). O mundo mudou. A Igreja, para continuar sendo a Igreja de sempre, também precisa mudar muito. Novos desafios exigem novas respostas pastorais ${ }^{22}$.

Agenor Brighenti explicita os fundamentos da "conversão pastoral" em Aparecida, no qual o objetivo dela é o agir da Igreja e seus agentes, e a razão, é a própria finalidade da evangelização, a salvação universal pela conexão com o Reino de Deus, do qual a Igreja é sinal e instrumento, isto é, seu sacramento. Quatro são os níveis da conversão pastoral: a) Conversão na consciência da comunidade: nível mais profundo da conversão pastoral e da renovação eclesial; b) Conversão na práxis pessoal e comunitária; c) Conversão nas relações de igualdade e autoridade e; d) Conversão das estruturas: as estruturas são também mensagem ${ }^{23}$.

Assim, a Igreja Católica na América Latina, consciente de que se está em uma mudança de época, reafirma que para uma "nova evangelização" a exigência é a "conversão pastoral", que consiste em passar de uma "pastoral de conservação" a uma pastoral decididamente evangelizadora. A questão é: como viabilizar essa ação evangelizadora da Igreja no contexto pós-moderno? O que, de fato, significa o imperativo de Aparecida de "conversão pastoral" no contexto novo?

\section{NOVOS CONTEXTOS, NOVOS SUJEITOS: NOVOS DESAFIOS PARA A IGREJA}

Em perfeita comunhão com a tradição latino-americana, no contexto pós-moderno emerge novos sujeitos teológicos que têm procurado dar continuidade ao processo de "recepção criativa" do Vaticano II. Neste horizonte de "recepção criativa" para que o Evangelho soe como Boa Nova neste novo contexto, o teólogo mexicano Carlos Mendoza Álvarez anuncia a exigência da "conversão epistêmica" e da "conversão ética" para todas as pessoas da comunidade ${ }^{24}$. Sem tal conversão não é possível levar a cabo os processos de humanização, pois se permanece fixado em um único modelo de ser humano que se impõe uniforme a todos sem, contudo, contemplar cada uma das subjetividades em jogo com suas diferenças específicas, de gênero, de língua, de crenças, de culturas, de tradição religiosa, etc.

\footnotetext{
${ }^{20} \mathrm{~V}$ CONFERÊNCIA GERAL DO EPISCOPADO LATINOAMERICANO. Aparecida. Documento de Conclusão, n. 365. Sobre este argumento, ver: BRIGHENTI A. A desafiante proposta, p. 19.

${ }^{21}$ V CONFERÊNCIA GERAL DO EPISCOPADO LATINOAMERICANO. Aparecida. Documento de Conclusão, n. 370.

${ }^{22}$ BRIGHENTI A. A desafiante proposta, p. 29.

${ }^{23}$ Cf. BRIGHENTI, A. Por uma evangelização realmente nova, p. 97-105.

${ }^{24}$ MENDOZA ÁLVAREZ, C. Deus ineffabilis. El linguaje sobre Dios em tempos de pluralismo cultural y religioso, p. 152.
} 
O imperativo da "conversão epistêmica e ética" é genuíno, exatamente porque os tempos pós-modernos se caracteriza pela busca da superação da razão moderna, no que tange a interpretação unívoca do real. A modernidade enfatizou a objetividade, o pensamento lógico e moral, leis universais, por outro lado, a pós-modernidade afirma que todo o conhecimento se deriva de cada ser que interpreta a realidade a partir de sua experiência. Por isso, não existe uma visão unívoca, universal e mundial. Não existe metanarrativa que nos une. Pelo contrário, a pós-modernidade celebra o local e o particular. E mais, ela insiste no respeito à diferença e ao pluralismo. Assim, a pós-modernidade resiste ao pensamento e comportamento unívoco porque valoriza grandemente o pluralismo. Ela celebra as diversidades e as diferença ${ }^{25}$.

Em outras palavras, o novo contexto é marcado pelo pensamento pós-hegemônico e pluralista, no qual não é mais possível sustentar no espaço público um discurso unilateral, tampouco unívoco, sobre a experiência do sagrado. Com efeito, estamos diante de uma nova racionalidade que interpela a Igreja, sobretudo na América Latina por sua característica constitutivamente plural e multiétnica ${ }^{26}$, à conversão epistêmica e ética $^{27}$. Neste novo contexto, surge a pergunta: Como falar de Deus em um contexto de pluralismo cultural e religioso? Como o cristianismo pode contribuir na tarefa comum da humanização onde o divino acontece?

O reconhecimento das diversas vozes, sejam pessoais ou comunitárias, nos ensina a falar desde o próprio lugar epistemológico, social, fenomenológico e teológico; sem o qual, não haverá diálogo. É necessário recuperar as micros-histórias que vão se conformando como subjetividades vulneráveis. A consciência da vulnerabilidade surgiu primeiramente como pensamento filosófico no século $\mathrm{XX}^{28}$. No Continente latinoamericano há outro acento. Mais que denunciar a epopeia do ego e seus naufrágios, busca-se descobrir - em plena comunhão com a tradição latino-americana que fez a opção preferencial pelos pobres- a "potência dos pobres e excluídos" 29 . Compreende-se que, os "pobres se reivindicam hoje como subjetividades com sua própria imaginação criativa, capazes de suscitar mudanças históricas revertendo o poder do metarrelato do mercado e o estado moderno que hoje impera no mundo globalizado" ${ }^{30}$.

Neste espaço intersubjetivo podemos encontrar pessoas honradas e discípulas de Jesus Cristo, como verdadeiros membros de sua "comunidade escatológica" ${ }^{31}$. Estes são os justos da história que são mediação para a salvação de toda a humanidade através da "difícil doação" 32 que realizam ao entregarem suas vidas até o último suspiro em prol da criação de um mundo novo.

São precisamente eles, os justos da história, quem nos sustenta na consciência agônica vivida como experiência de viver até o último suspiro. Uma existência niilista enquanto é vivida nos limites de si mesmo. Uma existência vivida como tal por um sujeito vulnerável porque se confrontou por experiência própria com uma vida que não cessa de olhar de frente para a morte ${ }^{33}$.

${ }^{25}$ TOLAND, E. M.M. La Misión Cristiana y la Cultura Postmoderna, 2013.

${ }^{26}$ TRIGO, P. Relaciones humanizadoras, p. 286-289.

${ }^{27}$ Neste sentido, as diversas etnias e culturas não ocidentais, tais como as indígenas e afro-ameríndias, lutam para que Nossa América deixe de definirse como latina, mas que se reconheçam o seu caráter multiétnico e pluricultural. Trata-se de uma luta por reconhecimento, que o reconhecimento que cada um faz de si inclua o reconhecimento dos demais como outros distintos e de igual dignidade (TRIGO, Pedro. 2013, p. 286-289).

${ }^{28}$ Os filósofos que expressaram a vulnerabilidade como pensamento foram: Paul Ricoeur que propôs uma hermenêutica do perdão como narração e esquecimento; Derrida como pensamento deconstrucionista e; também Richard Rorty, Gianni Vattimo e François Lytoard como pensamento pós-moderno. O teólogo mexicano Carlos Mendoza Álvarez apropria-se desse conceito derivado da fenomenologia, acrescido da instrumentalidade da antropologia de René Girard, especificamente a teoria do desejo mimético para produzir uma teologia fundamental pós-moderna.

${ }^{29}$ ROBERT, J.; RAHNEMA, M. La potencia de los pobres, 2012.

${ }^{30}$ MENDOZA ÁLVAREZ, Deus ineffabilis. El linguaje sobre Dios em tempos de pluralismo cultural y religioso, p. 133.

${ }^{31}$ MENDOZA ÁLVAREZ, Deus ineffabilis. El linguaje sobre Dios em tempos de pluralismo cultural y religioso, p. 133.

${ }^{32}$ CALDEIRA, C. Dá Europa à América Latina. A vulnerabilidade como locus theologicus, p. 318-323

${ }^{33}$ MENDOZA ÁLVAREZ, O Deus escondido, p. 191, grifo autor. 
Para o teólogo mexicano Carlos Mendoza Álvarez, portanto, uma fala pertinente sobre Deus hoje, em sentido epistemológico, no contexto de pluralismo cultural e religioso, como interpretação aberta ao diálogo, é possível a partir da assunção da vulnerabilidade constitutiva da subjetividade e das margens da história de dominação ${ }^{34}$. Enfim, dizer Deus no novo contexto se faz possível a partir da experiência teologal que realizam as subjetividades vulneráveis, isto é, das múltiplas resistências que realizam as vítimas da história fraturada da humanidade ${ }^{35}$. Nesse contexto, falar de Deus na pós-modernidade subtende necessariamente uma antropologia teológica do ser humano débil.

Neste horizonte da vulnerabilidade constitutiva, são as múltiplas resistências enquanto práticas e narrativas outras, que instauram um mundo mais justo e compassivo e, portanto, abrem caminho histórico de esperança para as vítimas primeiro, e depois para os verdugos. Por isso, são eles, os pobres e excluídos da história, que encarnam a concreção histórica da redenção realizada por Jesus de Nazaré, ao doarem suas vidas até o extremo, rompendo com a lógica da reciprocidade violenta por meio do perdão recebido e oferecido gratuitamente; superando o ressentimento e assumindo uma identidade reconciliada.

É possível falar de Deus em meio aos escombros da modernidade técnicocientífica somente se estivermos situados no clamor do sofrimento do inocente. Do lado das vítimas para clamar por justiça, sim, mas não somente. É preciso dar o último passo, que é postular um mundo alternativo a partir da superação do ressentimento [...] na gratuidade que só se entende como lógica da doação em um amor assimétrico e, nesse sentindo, não recíproco, difícil gratuidade sem dúvida ${ }^{36}$.

\section{CONSIDERAÇÕES FINAIS}

De fato, a emergência do novo contexto e seus respectivos sujeitos se impõe como grande desafio à Igreja, que carece de se ver em processos de uma "nova evangelização". A violência sistêmica é o grande desafio para que a mensagem do Evangelho soe como Boa Nova no contexto pós-moderno. Inserida em um processo de conversão epistemológica e ética, a Igreja na América Latina busca redescobrir a fonte de transcendência que se revela de maneira multiforme, isto é, no fundo da experiência de finitude; na capacidade da doação em meio à exploração e na luta por justiça; na culpabilidade assumida; na desgraça histórica, lugar onde acontece o amor incondicional que redime; na história de banalidade da violência onde surgem os justos da história, doando-se e redimindo a todos ${ }^{37}$.

A subjetividade vulnerável pós-moderna levantou um questionamento a todas as crenças sociais e humanas, inclusive à teologia, a saber: Como pensar o real "a partir do reverso da história"? Surge então, a importância de resgatar os micros-relatos como primeiro passo para se construir uma nova racionalidade capaz de dar conta das experiências humanas como "pessoas-em-relação" e, também, construir sociedades tolerantes e inclusivas.

\footnotetext{
${ }^{34}$ Cf. CALDEIRA, C. Teologia e niilismo pós-moderno: a subjetividade vulnerável como locus theologicus no pensamento de Carlos Mendoza Álvarez, p. 810-838.

${ }^{35}$ Cf. CALDEIRA, C. Dá Europa à América Latina. A vulnerabilidade como locus theologicus, p. 307-323.

${ }^{36}$ MENDOZA ÁLVAREZ, É possível falar de Deus, 2012.

${ }^{37}$ Cf. MENDOZA ÁLVAREZ, C. Deus ineffabilis. El linguaje sobre Dios em tempos de pluralismo cultural y religioso, p. 134.
} 
Nesta perspectiva, urge repensar as nossas "imagens de Deus", pois o mistério trinitário nos revela mais que uma doutrina a ser confessada, e sim um "viver em relação". Apropriando-se de conceitos pós-modernos, tais como a mecânica quântica, os princípios da indeterminação e a unidade da dualidade onda-partícula, possibilita apreciar e refletir sobre o verdadeiro mistério da profundidade da unidade e relacionalidade radical que existe na Trindade e na criação ${ }^{38}$. Nessa perspectiva, na qual tudo é relacional em profundidade de unidade trinitária, pode-se dizer que como seres humanos formamos um todo indivisível.

Seria possível descrever a teologia trinitária como a teoria da comunicação realizada entre as pessoas divinas em sua mútua reciprocidade. Dito de outro modo, trata-se da teoria da comunicação plena, no seio das diferenças entre sujeitos diversos que vivem a abertura extrema de um para com o outro: o Pai para com seu Filho, no reconhecimento mútuo do Espírito que os une ${ }^{39}$.

É no dinamismo trinitário revelado em e por Cristo que se pode encontrar esperança significativa para a sociedade pós-moderna. Não se trata de uma apologia a uma doutrina, mas sim um resgate do anúncio kerigmático intrínseco ao cristianismo, que se realiza inserido na história ambígua e contraditória dos seres humanos. Tal revelação mostra-nos que a comunicação plenamente realizada passa pela mediação existencial da doação enquanto renuncia ao si-mesmo. Da recepção criativa do Vaticano II, Medellín conseguiu atualizar a mensagem do Evangelho no Continente marcado pela exploração e opressão dos pobres e dos povos subjugados. E nisto consiste a nova evangelização, quando a Mensagem do Evangelho se torna boa nova de libertação e não simplesmente porque os conteúdos da fé são apresentados como um conjunto de verdades imutáveis.

Mas, mudando o contexto, mudam as perguntas, mudam os sujeitos. Assim, o contexto pós-moderno, através dos sujeitos vulneráveis, interpela a Igreja na América Latina a encarnar-se na realidade histórica ambígua e contraditória. Não somente isso. Mas, só assim a Igreja será capaz de enxergar os valores positivos da pós-modernidade e aceitar como pressuposto a pluralidade no Continente. O que a capacitará a apreciar o pluralismo cultural e religioso com ethos inevitável onde acontece a revelação divina.

\section{REFERÊNCIAS}

II CONFERÊNCIA GERAL DO EPISCOPADO LATINOAMERICANO. Medellín. Conclusões. A Igreja na atual transformação da América Latina à luz do Concílio, Petrópolis: Vozes, 1971.

III CONFERENCIA GENERAL DEL EPISCOPADO LATINO-AMERICANO, Puebla. Conclusões. Evangelização no presente e no futuro da América Latina. São Paulo: Paulinas, 1979.

V CONFERÊNCIA GERAL DO EPISCOPADO LATINOAMERICANO. Aparecida. Documento de Conclusão. São Paulo: Paulinas, 2007.

BEOZZO, José Oscar. "500 Anos de Evangelização da América Latina: o que podemos aprender de suas luzes e sombras”. Revista Eclesiástica Brasileira, Rio de Janeiro, v. 52, fasc. 206, p. 282-316. jun. 1992.

BOFF, Leonardo. “O Conflito dos Modelos de Evangelização para a América Latina: Reflexões a propósito dos 500 anos”. Revista Eclesiástica Brasileira, Rio de Janeiro. v. 52, fasc. 206, p. 344-386. jun. 1992.

\footnotetext{
${ }^{38}$ Cf. TOLAND, E. M. M. La Misión Cristiana, 2013.
}

${ }^{39}$ MENDOZA ÁlVAREZ, C. O Deus escondido, p. 206. 
BRIGHENTI, Agenor. A Igreja na América Latina e a "recepção criativa" do Concílio Vaticano II. In: União Marista do Brasil - UMBRASIL. (Org.). Utopias do Vaticano II. Que sociedade queremos? Diálogos. São Paulo: Paulinas, 2013. p. 229-255.

Por uma evangelização realmente nova. Perspectiva Teológica, Belo Horizonte, v. 45, n. 125, p. 83-106, jan.-abr. 2013.

Nueva y antiga evangelización. El imperativo de una conversión pastoral. Efemérides Mexicana, México, v. 31, p. 67-101, 2013.

. A desafiante proposta de Aparecida. São Paulo: Paulinas, 2007.

CALDEIRA, Cleusa. Teologia e niilismo pós-moderno: a subjetividade vulnerável como locus theologicus no pensamento de Carlos Mendoza Álvarez. Revista Pistis \& Práxis, v. 9, n. 3, p. 810-838. 2018. DOI: 10.7213/2175-1838.09.003.AO05

Dá Europa à América Latina. A vulnerabilidade como locus theologicus. Revista Perspectiva Teológica, v. 50, n. 2, p. 307-323, 2018. DOI: 10.20911/21768757v50n2p307/2018

CONFERÊNCIA GERAL DO EPISCOPADO LATINOAMERICANO. Conclusões da Conferência de Medellin, 1968: trinta anos depois, Medellín é ainda atual? São Paulo: Paulinas, 2010.

DUQUOC, C. Je crois em l'Église. Précarité institucionelleet Règne de Dieu. Paris: Cerf, 1999.

MELGUIZO YEPES, Guilhermo. La nueva evangelización 1965-2012. Del Vaticano II ao Sínodo de la nueva evagelización para la transformasión de la fé. Medellín, v. 38, n. 149, p. 7-25, jan.-mar. 2012.

MENDOZA-ÁLVAREZ, Carlos. Deus ineffabilis. El linguaje sobre Dios em tempos de pluralismo cultural y religioso. In: OLIVEIRA, Pedro A. Ribeiro de; DE MORI, Geraldo (Org.). Deus na Sociedade Plural: fé, símbolos, narrativas. Belo Horizonte: Soter/Paulinas, 2013. p. 129-153.

Extra Victimas Salus non est o de la vigência da la teologia de la liberación em tiempos posmodernos. In: BRIGHENTI, Agenor; HERMANO, Rosario (Org.). 50 años de Vaticano II. Análisis y perspectivas. Memorias del Congreso Continental de Teología. Colombia: Paulinas, 2013. p. 192-203.

O Deus escondido da pós-modernidade: desejo, memória e imaginação escatológica. Ensaio

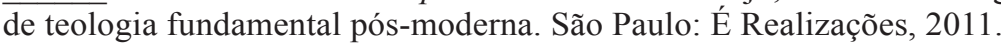

É possível falar sobre Deus na sociedade contemporânea? Entrevista especial com Carlos Mendoza Álvarez. Instituto Humanitas Unisinos (30.09.2012). Disponível em: < http://www.ihu. unisinos.br/entrevistas/514111-e-possivel-falar-de-deus-na-contemporaneidade-entrevista-especialcom-carlos-mendoza-alvarez>. Acesso em: 15 maio 2013.

MIRANDA, Mário de França. Em vista da nova evangelização. Perspectiva Teológic, Belo Horizonte. v. 45, n. 125, p. 13-34. jan.-abr. 2013.

PAULO VI. Exortação Apostólica Pós-Sinodal Evangelii nuntiandi (8.12.1975). São Paulo: Paulinas, 1975.

ROBERT, Jean; RAHNEMA, Majid. La potencia de los pobres. Cideci-Unitierra: San Cristóbal de Las Casas, 2012.

TABORDA, Francisco S. J. Evangelizacion para el tercer milênio. Santafé de Bogotá: Indo-American Press Service, 1994.

TOLAND, Eugenio M. M. La Misión Cristiana y la Cultura Postmoderna. Disponível em: $<$ http:// amerindiaenlared.org/noticia/290/-la-mision-cristiana-y-la-cultura-postmoderna/>. Acesso em: 21 set. 2013.

TRIGO, Pedro. Relaciones humanizadoras: um imaginario alternativo. Santiago de Chile: Universidad Alberto Hurtado, 2013.

Recebido em: 25/10/2018

Aprovado em: 21/11/2018

Correspondência para:

Dr- Cleusa Caldeira

Rua Amapá, 951 - Bairro Centro

CEP 87703-380 Paranavaí, PR, Brasil 